\title{
Article \\ Serum C18:1-Cer as a Potential Biomarker for Early Detection of Gestational Diabetes
}

\author{
Ilona Juchnicka ${ }^{1}$, Mariusz Kuźmicki ${ }^{1, *}$, Piotr Zabielski ${ }^{2}$, Adam Krętowski ${ }^{3,4}$, Agnieszka Błachnio-Zabielska ${ }^{5}$ (D) \\ and Jacek Szamatowicz ${ }^{1}$
}

check for

updates

Citation: Juchnicka, I.; Kuźmicki, M.; Zabielski, P.; Krętowski, A.; Błachnio-Zabielska, A.; Szamatowicz, J. Serum C18:1-Cer as a Potential Biomarker for Early Detection of Gestational Diabetes. J. Clin. Med. 2022, 11, 384. https://doi.org/ $10.3390 / j \mathrm{~cm} 11020384$

Academic Editor: Basilio Pintaudi

Received: 8 December 2021

Accepted: 10 January 2022

Published: 13 January 2022

Publisher's Note: MDPI stays neutral with regard to jurisdictional claims in published maps and institutional affiliations.

Copyright: () 2022 by the authors Licensee MDPI, Basel, Switzerland. This article is an open access article distributed under the terms and conditions of the Creative Commons Attribution (CC BY) license (https:/ / creativecommons.org/licenses/by/ $4.0 /)$.
1 Department of Gynecology and Gynecological Oncology, Medical University of Bialystok, 15-276 Bialystok, Poland; ilona.sikora@ubm.edu.pl (I.J.); ginekol@ubm.edu.pl (J.S.)

2 Department of Medical Biology, Medical University of Bialystok, 15-276 Bialystok, Poland; biollek@umb.edu.pl

3 Department of Endocrinology, Diabetology and Internal Medicine, Medical University of Bialystok, 15-276 Bialystok, Poland; ednodiab@umb.edu.pl

4 Clinical Research Centre, Medical University of Bialystok, 15-276 Bialystok, Poland

5 Department of Hygiene, Epidemiology and Metabolic Disorders, Medical University of Bialystok, 15-276 Bialystok, Poland; higienametz@umb.edu.pl

* Correspondence: mariusz.kuzmicki@umb.edu.pl

\begin{abstract}
We hypothesized that sphingolipids may be early biomarkers of gestational diabetes mellitus (GDM). Here, 520 women with normal fasting plasma glucose levels were recruited in the first trimester and tested with a $75 \mathrm{~g}$ oral glucose tolerance test in the 24 th-28th week of pregnancy. Serum sphingolipids concentrations were measured in the first and the second trimester by ultra-high performance liquid chromatography coupled with triple quadrupole mass spectrometry (UHPLC/MS/MS) in 53 patients who were diagnosed with GDM, as well as 82 pregnant women with normal glucose tolerance (NGT) and 32 non-pregnant women. In the first trimester, pregnant women showed higher concentrations of C16:0, C18:1, C22:0, C24:1, and C24:0-Cer and lower levels of sphinganine (SPA) and sphingosine-1-phosphate (S1P) compared to non-pregnant women. During pregnancy, we observed significant changes in C16:0, C18:0, C18:1, and C24:1-Cer levels in the GDM group and C18:1 and C24:0-Cer in NGT. The GDM (pre-conversion) and NGT groups in the first trimester differed solely in the levels of C18:1-Cer (AUC $=0.702 p=0.008$ ), also considering glycemia. Thus, C18:1-Cer revealed its potential as a GDM biomarker. Sphingolipids are known to be a modulator of insulin resistance, and our results indicate that ceramide measurements in early pregnancy may help with GDM screening.
\end{abstract}

Keywords: gestational diabetes; sphingolipids; ceramides; lipidomic; C18:1-Cer

\section{Introduction}

Gestational diabetes mellitus (GDM) is defined as glucose intolerance first recognized during pregnancy. It is usually the result of $\beta$-cell dysfunction on a background of chronic insulin resistance [1]. Other factors affecting insulin sensitivity are maternal obesity, extensive hormones release, adipocytokine production, genetic and epigenetic changes, and novel potential omics factors [2]. Hyperinsulinemic-euglycemic clamp studies in healthy, lean women show that insulin sensitivity is reduced by $56 \%$ compared with pre-pregnancy, and basal endogenous glucose production is increased by $30 \%$ in the third trimester $[3,4]$. During pregnancy, we observe an increase in lipid concentration, especially in triglycerides, and, to a lesser extent, phospholipids and cholesterol. It is the result of altered maternal metabolism [5].

Insulin resistance and hyperlipidemia are important physiological processes essential during pregnancy to ensure sufficient fetal nutrition. In women with GDM, the physiological changes in insulin and lipids are excessive but also transitional and may indicate 
underlying metabolic dysfunction [6,7]. As is well known, lipids perform a crucial role in the biology of the human body, not only being an energy storage and a component of cell membranes, but also acting as an agent in signaling pathways and altering the metabolism. Disturbances in lipid metabolic signaling pathways are associated with inflammation and systemic diseases such as the metabolic syndrome and hypertension [8]. Population-based lipidomic studies indicate that a number of ceramides (Cers), sphingomyelins, and lactosyloceramides are significantly downregulated years before type 2 diabetes onset, suggesting that the downregulation of sphingolipid metabolism could be partially responsible for the future onset of type 2 diabetes among women with GDM history [9]. Furse et al. showed that lipid metabolism was altered at least 10 weeks before a clinical diagnosis of GDM was made [10].

Sphingolipids are a group of biologically active lipids involved in regulation of various cellular processes including cell migration, inflammatory response, proliferation, differentiation, and apoptosis [11,12]. The central molecule in sphingolipid metabolism and the precursor for the complex sphingolipids is ceramide. Available data suggest that it is also a major contributing factor of insulin resistance in skeletal muscles and the liver [13-15]. These compounds induce insulin resistance at the level of RAC $\alpha$ serine/threonine-protein kinase, also known as Akt or protein kinase B-PKB [16]. This compound activates protein phosphataseA2 (PPA2) and directly catalyzes PKB/Akt dephosphorylation, thus, inhibiting the activity of the insulin pathway [16]. Moreover, type 2 diabetes is often associated with chronic, moderate inflammation. Sphingosine-1-phosphate (S1P) belongs to the sphingolipid family and is a pro-inflammatory compound that increases the expression and secretion of cytokines (e.g., TNF $\alpha$, IL-6, MCP-1) [17]. However, the effect of S1P on the inflammatory response has been demonstrated to be dependent on a carrier protein. The major carrier proteins for S1P are apolipoprotein M (apoM) and albumin. Most of the plasma S1P is bound to the apoM/ApoM-S1P that binds preferentially to HDL. ApoM-S1P has been shown to inhibit inflammatory responses in endothelial cells [18]. These features suggest that S1P may induce the disorders leading to GDM, but there is little literature data on this subject.

Here, we hypothesized that circulating sphingolipids may be early biomarkers of GDM development. To test this hypothesis, serum sphingolipid levels were measured in the first and the second trimester and compared between the patients with normal glucose tolerance (NGT) and GDM diagnosed between 24 and 28 weeks of pregnancy.

\section{Materials and Methods}

\subsection{Study Population}

Women $(n=520)$ with normal fasting plasma glucose levels $(<92 \mathrm{mg} / \mathrm{dL}(5.1 \mathrm{mmol} / \mathrm{L}))$ were recruited in the first trimester of pregnancy from the Gynecological Out-Patient Clinic of the Medical University of Bialystok. Women with a history of GDM, stillbirth, congenital anomalies, pregnancy-induced hypertension, multiple pregnancy, pre-existing glucose intolerance, or acute or chronic inflammation and active smokers were not included. All patients underwent a $75 \mathrm{~g}$ oral glucose tolerance test (OGTT) in the 24th-28th week of pregnancy and gestational diabetes was diagnosed in 53 women (GDM) according to the WHO 2013 criteria [19]. Their results were compared with the results of the carefully selected 82 pregnant women with normal glucose tolerance (NGT). We also enrolled a third control group that consisted of 37 healthy, non-pregnant women. All groups were matched for age, and pre-pregnancy BMI was calculated as weight in kilograms divided by height in meters. Written informed consent was obtained from all participants before enrolment, and the protocol was approved by the local ethics committee (Medical University of Bialystok).

\subsection{Diabetic Parameters}

In the 1st trimester, venous blood samples were collected in the fasting state. Serum was collected by allowing freshly drawn blood to clot, followed by centrifugation at $2000 \times g$ for $10 \mathrm{~min}$ in a refrigerated centrifuge. The resulting supernatant was collected and stored 
at $-80^{\circ} \mathrm{C}$ until further analysis. The $75 \mathrm{~g}$ oral glucose tolerance test (OGTT) was performed in the 24th-28th week of pregnancy in the pregnant patients, as well as in the control group, after an overnight fast. Blood samples were collected at 0, 30, 60, and 120 min after glucose load. Plasma glucose concentration was measured via an enzymatic method with hexokinase (Cobas c111, Roche Diagnostics Ltd., Switzerland). Serum insulin levels were assayed by immunoradiometric method (DiaSource Europe SA, Belgium), and glycated hemoglobin (HbA1c) was evaluated with a high-performance liquid chromatography technique (BIO-RAD Laboratories, Germany). The following indices of insulin sensitivity and insulin secretion were calculated: (1) HOMA-IR (the homeostasis model assessment of insulin resistance $)=\mathrm{FPG}(\mathrm{mmol} / \mathrm{L}) \times \mathrm{FPI}(\mu \mathrm{U} / \mathrm{mL}) / 22.5$, HOMA $-\beta[\%]=20 \times$ FPI $(\mathrm{mU} / \mathrm{L}) / \mathrm{FPG}(\mathrm{mmol} / \mathrm{L})-3.5$; and (2) the Matsuda and de Fronzo in$\operatorname{dex}(\mathrm{ISOGTT})=10,000 / \sqrt{ }((\mathrm{FPG} \times \mathrm{FPI}) \times(\mathrm{G} \times \mathrm{I}))$, where FPG $=$ fasting plasma glucose, $\mathrm{FPI}=$ fasting plasma insulin, $\mathrm{G}=$ mean glucose, and $\mathrm{I}=$ mean insulin during the OGTT [20]. Total cholesterol, HDL-cholesterol, and triglyceride concentrations were measured by enzymatic methods (Cobas c111, Roche Diagnostics Ltd., Rotkreuz, Switzerland). LDL-cholesterol concentration was calculated using the Friedewald equation.

\subsection{Sphingolipid Measurements}

The concentration of serum sphingolipids was measured in the first and the second trimester of pregnancy using a UHPLC/MS/MS approach according to BłachnioZabielska et al. [21]. Briefly, an internal standard mix (17C-sphingosine, 17C-S1P, d17:1/8:0, d17:1/18:0, d17:1/18:1 (9Z), d17:1/20:0, d17:1/24:0, and d17:1/24:1 (15Z)) (Avanti Polar Lipids, Alabaster, Al), as well as an extraction mixture (isopropanol:water:ethyl acetate, 30:10:60; v:v:v), was added to each serum sample. The samples were vortexed and then centrifuged. The supernatants were transferred to new tubes and pellets were re-extracted. After centrifugation, supernatants were combined and evaporated under nitrogen. The dried samples were reconstituted in LC Solvent B (2 mM ammonium formate, $0.15 \%$ formic acid in methanol) for UHPLC/MS/MS analysis (Sciex 6500+; AB Sciex Germany GmbH, Darmstadt, Germany). The chromatographic separation was performed on a reverse-phase Zorbax SB-C8 column $2.1 \times 150$ mm, $1.8 \mu \mathrm{m}$ (Agilent Technologies, Santa Clara, CA, USA) in a binary gradient using $1 \mathrm{mM}$ ammonium formate with $0.1 \%$ formic acid in water as solvent $\mathrm{A}$ and $2 \mathrm{mM}$ ammonium formate and $0.1 \%$ formic acid in methanol as solvent $\mathrm{B}$ at the flow rate of $0.4 \mathrm{~mL} / \mathrm{min}$. Sphingolipids concentrations were analyzed via a triple quadrupole mass spectrometer using positive ion electrospray ionization (ESI) (except for $\mathrm{S} 1 \mathrm{P}$, which was analyzed in negative mode) with multiple reaction monitoring (MRM) against the concentration standard curves.

\subsection{Statistical Analysis}

The data were analyzed by the STATISTICA 13 for Windows (StatSoft. Inc., Tulsa, OK, USA). Data were shown as medians and interquartiles. Differences between the two groups were compared by Mann-Whitney U test, differences between all three groups were compared via a Kruskal-Wallis test, and relationships between variables were tested by Spearman's correlations. A Wilcoxon signed rank test was used to compare sphingolipids levels in the 1st and 2nd trimester. A p-value less than 0.05 was considered statistically significant. Data are shown as medians with interquartile ranges.

\section{Results}

\subsection{Characteristics of the Studied Groups}

Tables 1 and 2 compare the clinical and biochemical characteristics of the study patients. 
Table 1. Clinical characteristics of the groups studied in the 1st trimester.

\begin{tabular}{|c|c|c|c|c|}
\hline & Control & NGT & GDM (Pre-Conversion) & $p$-Value \\
\hline$n$ & 37 & 82 & 53 & \\
\hline Age (years) & $26(23-31)$ & $28(24-32)$ & $25.5(24-30)$ & $\begin{array}{l}0.4^{\circ} \\
0.81^{*}\end{array}$ \\
\hline Gestational age (week) & & $11(10-12)$ & $11(10-11)$ & $0.19 *$ \\
\hline Prepregnancy BMI $\left(\mathrm{kg} / \mathrm{m}^{2}\right)$ & $21.9(20.6-23.4)$ & $20.9(19.8-28.5)$ & $24.1(21.6-26.8)$ & $\begin{array}{l}0.42^{\circ} \\
0.87^{*}\end{array}$ \\
\hline Current BMI $\left(\mathrm{kg} / \mathrm{m}^{2}\right)$ & & $24.5(20.4-29.8)$ & $24.8(22.0-26.7)$ & $0.95 *$ \\
\hline Fasting glucose (mg/dL) & $90(86-92)$ & $86(84-88)$ & $87(84.5-89.5)$ & $\begin{array}{c}0.0005^{\circ} \\
0.19^{*}\end{array}$ \\
\hline Fasting insulin $(\mu \mathrm{U} / \mathrm{mL})$ & $7.5(5.2-10.7)$ & $11.6(8.9-14.7)$ & $11.3(10.1-13.3)$ & $\begin{array}{c}<0.0001^{\circ} \\
0.83^{*}\end{array}$ \\
\hline HOMA-IR & $1.6(1.1-2.4)$ & $2.4(1.8-3.2)$ & $2.5(2.1-2.9)$ & $\begin{array}{c}0.0002^{\circ} \\
0.89\end{array}$ \\
\hline HOMA- $\beta$ & $101.1(67.3-149)$ & $176.9(151.9-226.8)$ & $173.7(155.7-220.0)$ & $\begin{array}{c}<0.0001^{\circ} \\
0.82^{*}\end{array}$ \\
\hline HbA1c (\%) & $5.2(5.0-5.4)$ & $5.0(4.9-5.3)$ & $5.1(4.9-5.4)$ & $\begin{array}{c}0.2^{\circ} \\
0.31^{*}\end{array}$ \\
\hline Total cholesterol (mmol/L) & $166(158-182)$ & $174(150-202)$ & $172(156.5-187)$ & $\begin{array}{l}0.64^{\circ} \\
0.64^{*}\end{array}$ \\
\hline HDL-cholesterol (mmol/L) & $86(69.6-102.8)$ & $73(63-88)$ & $72.5(59.5-80.5)$ & $\begin{array}{l}0.01^{\circ} \\
0.49^{*}\end{array}$ \\
\hline LDL-cholesterol (mmol/L) & $64(53-83)$ & $78(63.4-96.6)$ & $87.6(69.3-95.5)$ & $\begin{array}{l}0.03^{\circ} \\
0.79^{*}\end{array}$ \\
\hline Triglycerides (mmol/L) & $69(59-75)$ & $87(65-116)$ & 84.5 (64.5-125.5) & $\begin{array}{c}0.0009^{\circ} \\
0.92^{*}\end{array}$ \\
\hline
\end{tabular}

Data are shown as medians (interquartile range); ${ }^{\circ}$ differences between all groups were analyzed by Kruskal-Wallis test. * The difference between NGT and GDM groups was compared by Mann-Whitney U test.

Table 2. Clinical characteristics of the groups studied in the 2nd trimester.

\begin{tabular}{|c|c|c|c|}
\hline & NGT & GDM & $p$-Value \\
\hline$n$ & 82 & 53 & \\
\hline Gestational age (week) & $25(24-26)$ & $25.5(24-26)$ & 0.41 \\
\hline Current BMI $\left(\mathrm{kg} / \mathrm{m}^{2}\right)$ & $26.17(22.6-31.8)$ & $27.8(23.7-29.7)$ & 0.76 \\
\hline Fasting glucose (mg/dL) & $83(80-86)$ & $94(89-97)$ & $<0.0001$ \\
\hline Glucose 30' (mg/dL) & 127 (117-139) & $157.5(139.5-166)$ & $<0.0001$ \\
\hline Glucose $60^{\prime}(\mathrm{mg} / \mathrm{dL})$ & $121.5(103-139)$ & $164(129.5-184)$ & $<0.0001$ \\
\hline Glucose $120^{\prime}(\mathrm{mg} / \mathrm{dL})$ & $108(89-121)$ & $124(113-157)$ & $<0.0001$ \\
\hline Fasting insulin $(\mu \mathrm{U} / \mathrm{mL})$ & $11.1(9.2-14.2)$ & $15.9(12.8-20.5)$ & $<0.0001$ \\
\hline Insulin $30^{\prime}(\mu \mathrm{U} / \mathrm{mL})$ & $77.9(56.2-115.1)$ & $89.3(61.1-137.3)$ & 0.18 \\
\hline Insulin $60^{\prime}(\mu \mathrm{U} / \mathrm{mL})$ & $72.3(47.9-112.8)$ & $108.3(91.1-152.4)$ & $<0.0001$ \\
\hline Insulin $120^{\prime}(\mu \mathrm{U} / \mathrm{mL})$ & $56.0(35.2-78.0)$ & $104.8(68.7-131)$ & $<0.0001$ \\
\hline HOMA-IR & $2.3(1.9-2.9)$ & $3.6(2.8-4.7)$ & $<0.0001$ \\
\hline HOMA- $\beta$ & $223.2(169.8-276.1)$ & $201.4(154.4-244.3)$ & 0.13 \\
\hline ISI OGTT & $4.3(3.3-5.4)$ & $2.6(2.1-3.4)$ & $<0.0001$ \\
\hline $\mathrm{HbA1c}(\%)$ & $4.8(4.7-5.1)$ & $5.0(4.8-5.2)$ & 0.006 \\
\hline Total cholesterol (mmol/L) & $243(219-276)$ & $233(203-257)$ & 0.04 \\
\hline HDL-cholesterol (mmol/L) & $86(73-95)$ & $79(65-93)$ & 0.13 \\
\hline LDL-cholesterol (mmol/L) & $120.4(95.6-149.2)$ & $119.2(86.8-134.4)$ & 0.08 \\
\hline Triglycerides (mmol/L) & $172(133-196)$ & 179 (136-219) & 0.31 \\
\hline
\end{tabular}

Data are shown as medians (interquartile range); the difference between NGT and GDM groups was compared the Mann-Whitney U test.

In the first trimester, the patients who were later diagnosed with GDM (converters) had no significant differences compared with the women with NGT (Table 1). The comparison of the three groups revealed significant differences between fasting glucose levels $(p<0.001)$, which is a consequence of a variation in norms (19). Fasting insulin $(p<0.001)$, HOMA-IR 
$(p<0.001)$, HOMA- $\beta(p<0.001)$, and triglycerides levels $(p<0.001)$ were higher in both pregnant women groups; HDL-cholesterol $(p=0.01)$ was higher in the control group.

In the second trimester, the GDM converters had significantly higher fasting and postload glucose concentration $(p<0.001)$; higher fasting and post-load insulin concentrations $(p<0.001)$ except for insulin $30^{\prime}$, as well as higher HOMA-IR $(p<0.001)$ and $\mathrm{HbA} 1 \mathrm{c}$ $(p=0.006)$. Furthermore, GDM converters had lower ISI OGTT $(p<0.001)$ and lower total cholesterol levels $(p=0.04)$ versus the NGT group (Table 2).

\subsection{Sphingolipids Profile}

The concentration of total serum ceramides was significantly lower in non-pregnant women versus pregnant ones ( $p=0.0006$ versus the GDM pre-conversion and $p<0.0001$ versus the NGT group). The control group had lower levels of C16:0-Cer ( $p=0.02 \mathrm{vs.} \mathrm{GDM}$ pre-conversion and $p=0.0002$ vs. NGT), C18:1-Cer ( $p<0.0001$ vs. GDM pre-conversion and $p=0.006$ vs. NGT), C22:0-Cer ( $p<0.0001$ in both comparisons), C24:1-Cer ( $p=0.0001$ vs. GDM pre-conversion and $p<0.0001$ vs. NGT), and C24:0-Cer ( $p=0.03$ vs. GDM preconversion and $p=0.003 \mathrm{vs}$. NGT). The control group had higher sphinganine (SPA) and S1P levels ( $p<0.0001$ in both comparisons vs. GDM pre-conversion and the NGT group).

Among the pregnant women, comparisons between the GDM converter group and the NGT group using the Mann-Whitney U test revealed prominent differences in C18:1 concentration $(p=0.01)$ (Table 3, Figure 1). The diagnostic value of this ceramides species was evaluated by ROC analysis. The values of AUC and optimal cut-off value for C18:1-Cer were as follows: 0.702 confidence interval: $0.552-0.852, p=0.008$ (Figure 2).

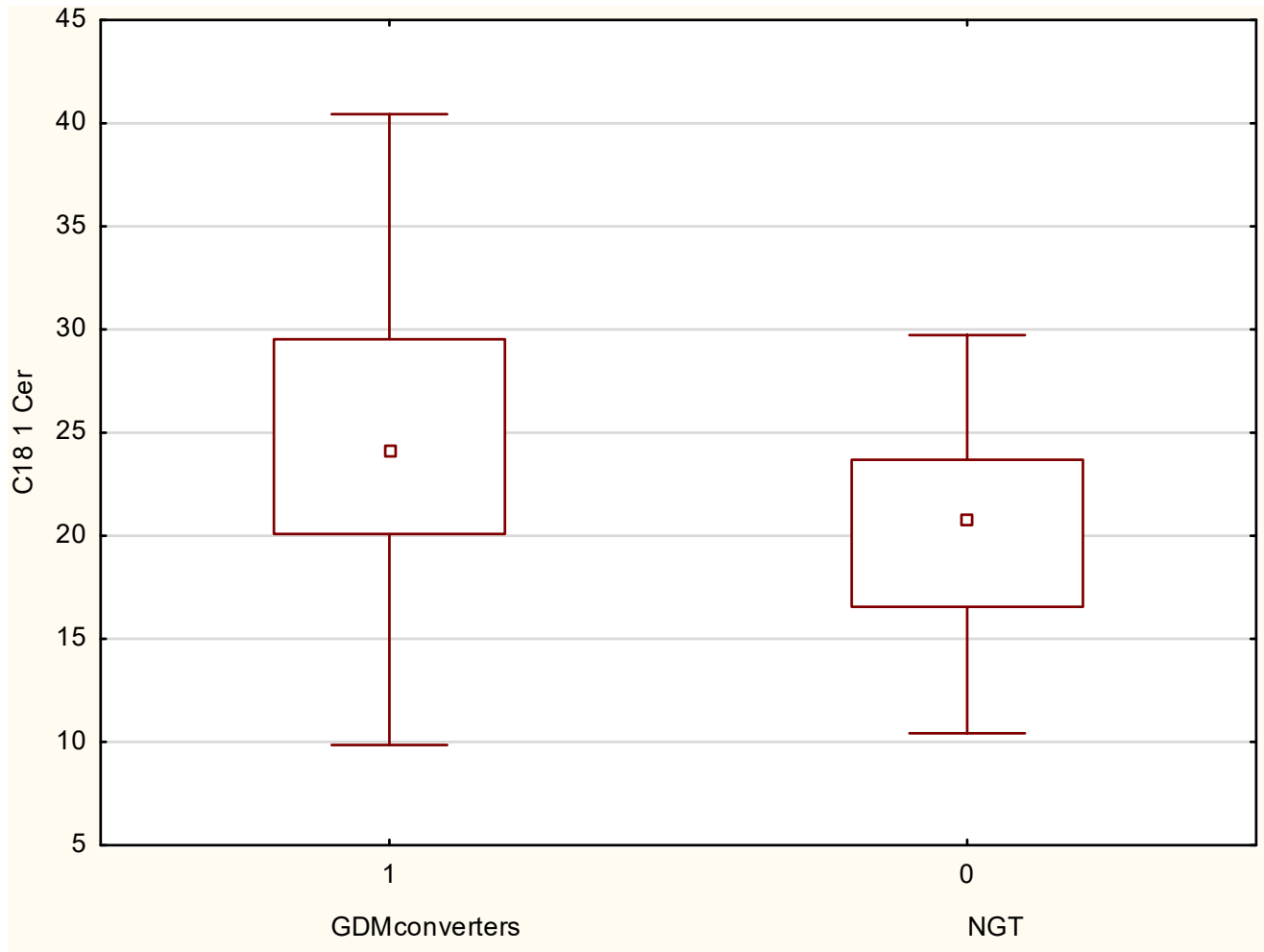

Figure 1. Serum C18:1-Cer concentrations measured in the first trimester of pregnancy. Data are shown as medians and interquartile range. 
Youdena index $=0.34$

Suggested cut off point: 23.86

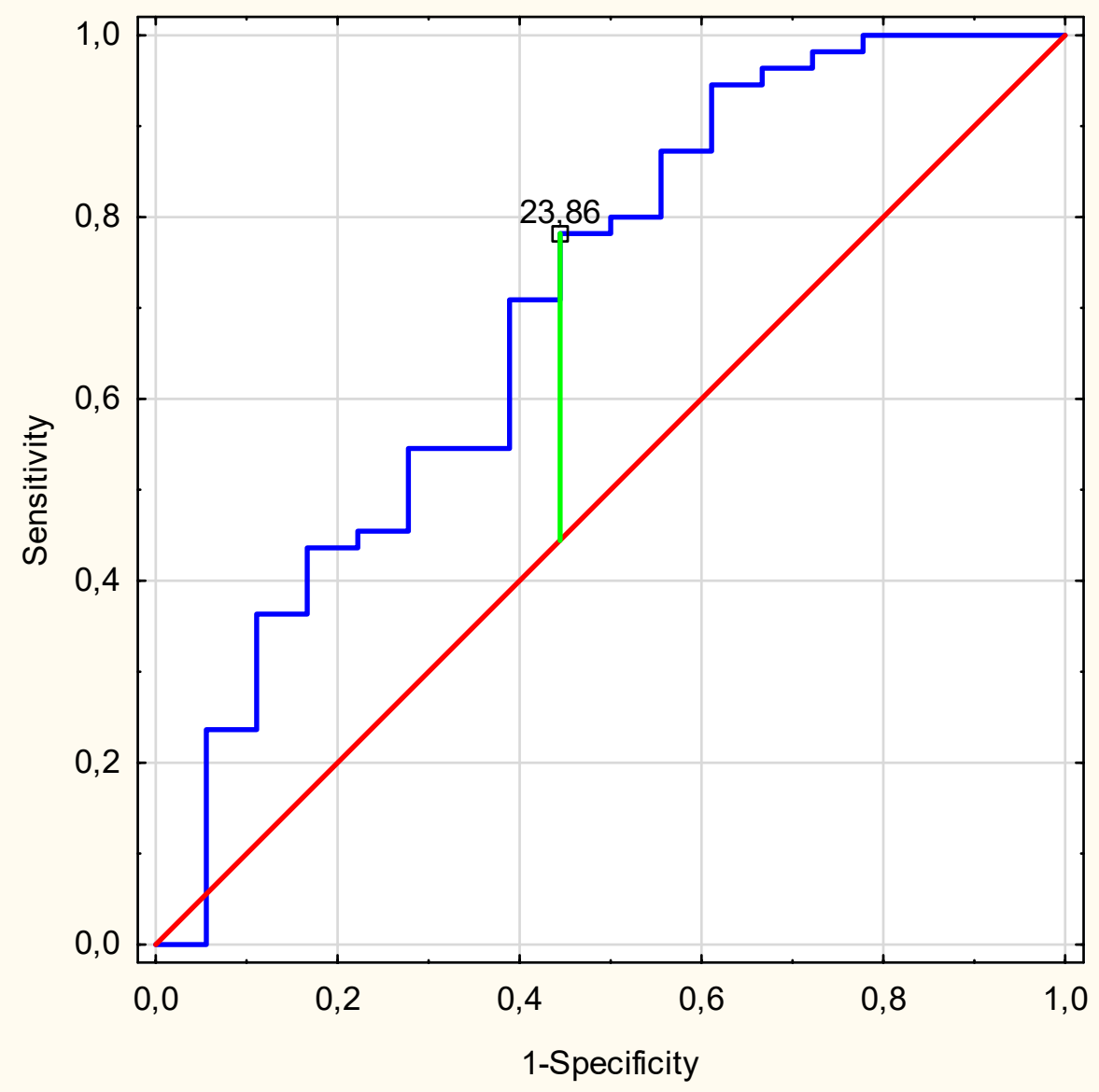

Figure 2. ROC curve for C18:1-Cer measured in the 1st trimester of pregnancy (AUC $=0.702$ (95\% confidence interval: $0.552-0.852 ; p=0.008$ ) with optimal cut-off value of $23.87 \mathrm{ng} / \mathrm{mL}$ ). 
Table 3. The concentration of sphingolipids in the serum of patients in the non-pregnant control group and pregnant GDM pre-conversion and NGT group in their 1st trimester.

\begin{tabular}{|c|c|c|c|c|}
\hline \multirow{2}{*}{ Compound } & \multirow{2}{*}{$\begin{array}{c}\text { Control Group } \\
\text { Me (Q1-Q3) [ng/mL] }\end{array}$} & \multirow{2}{*}{$\begin{array}{c}\text { NGT } \\
\text { Me (Q1-Q3) [ng/mL] }\end{array}$} & \multirow{2}{*}{$\begin{array}{c}\text { GDM Pre-Conversion } \\
\text { Me (Q1-Q3) [ng/mL] }\end{array}$} & \multirow[t]{2}{*}{$p$-Value } \\
\hline & & & & \\
\hline Sph & $23.4(20.6-26.4)$ & $18.02(13.3-31.7)$ & $17.2(14.5-36.9)$ & $\begin{array}{c}{ }^{*} p=0.73 \\
\circ p=0.2 \\
\wedge p=0.09\end{array}$ \\
\hline SPA & $37.5(34.2-43.8)$ & 13.89 (9.9-19.7) & $10.82(8.0-20.2)$ & $\begin{array}{c}* p=0.28 \\
\circ p<0.0001 \\
\wedge p<0.0001\end{array}$ \\
\hline S1P & $400.93(357.2-436.8)$ & 348.81 (251.4-403.4) & 296.78 (235.3-342.4) & $\begin{array}{c}* p=0.06 \\
\circ p<0.0001 \\
\wedge p<0.0001\end{array}$ \\
\hline C14:0 Cer & $30.56(26.5-34.7)$ & $32.4(25.6-42.9)$ & $29.6(23.4-36.7)$ & $\begin{array}{c}{ }^{*} p=0.22 \\
{ }^{\circ} p=0.5 \\
\wedge p=0.19\end{array}$ \\
\hline C16:0 Cer & 135.68 (118.6-156.6) & 183.37 (151.3-246.6) & 178.01 (129.9-201.4) & $\begin{array}{c}* p=0.49 \\
\circ p=0.02 \\
\wedge p=0.0002\end{array}$ \\
\hline C18:1 Cer & 16.33 (14.3-18.5) & $20.72(16.6-23.7)$ & $24.16(20.1-29.5)$ & $\begin{array}{c}{ }^{*} p=0.01 \\
\circ p<0.0001 \\
\wedge p=0.006\end{array}$ \\
\hline C18:0 Cer & 127.75 (114.3-142.2) & 133.01 (108.4-160.5) & 132.87 (108.1-199.6) & $\begin{array}{l}{ }^{*} p=0.57 \\
{ }^{\circ} p=0.6 \\
\wedge p=0.5\end{array}$ \\
\hline C20:0 Cer & 183.56 (156.4-206.7) & 172.96 (130.1-194.2) & 152.08 (123.6-177.9) & $\begin{array}{l}{ }^{*} p=0.25 \\
{ }^{\circ} p=0.09 \\
\wedge p=0.3\end{array}$ \\
\hline C22:0 Cer & 215.53 (198.3-240.4) & 280.68 (243.5-317.7) & 316.04 (256.0-376.7) & $\begin{array}{c}* p=0.1 \\
\circ p<0.0001 \\
\wedge p<0.0001\end{array}$ \\
\hline C24:1 Cer & 219.88 (200.8-251.5) & 280.36 (237.9-336.5) & $278.96(241.5-320.3)$ & $\begin{array}{c}{ }^{*} p=0.92 \\
\circ p=0.0001 \\
\wedge p<0.0001\end{array}$ \\
\hline C24:0 Cer & 1941.61 (1819.1-2306.9) & $2200.14(2040.8-2608.7)$ & $2356.23(2026.8-2917.9)$ & $\begin{array}{c}{ }^{*} p=0.52 \\
\circ p=0.03 \\
\wedge p=0.003\end{array}$ \\
\hline Cer Total & $3023.67(2738.7-3225.9)$ & 3344.21 (3101.9-3682.7) & 3552.17 (3007.1-3923.5) & $\begin{array}{c}{ }^{*} p=0.39 \\
{ }^{\circ} p=0.0006 \\
\wedge p<0.0001\end{array}$ \\
\hline
\end{tabular}

Data are presented as medians (interquartile range). Analysis was performed with the Mann-Whitney U test. * GDM vs. NGT; ${ }^{\circ}$ GDM vs. control; ${ }^{\wedge}$ NGT vs. control.

Across the study population, the SPA concentration correlated negatively with serum insulin $(\mathrm{R}=-0.33, p<0.05)$, HOMA-IR $(\mathrm{R}=-0.3, p<0.05)$, and HOMA- $\beta(\mathrm{R}=-0.38$, $p<0.05)$. Positive correlations with serum insulin parameters were observed in $\mathrm{C} 22: 0-$ Cer with insulin $(\mathrm{R}=0.3, p<0.05)$, HOMA-IR $(\mathrm{R}=0.3, p<0.05)$, and HOMA- $\beta(\mathrm{R}=0.31$, $p<0.05)$; C24:0-Cer correlated with insulin $(\mathrm{R}=0.27, p<0.05)$, HOMA-IR $(\mathrm{R}=0.23, p<0.05)$, and HOMA- $\beta(\mathrm{R}=0.32, p<0.05)$. Furthermore, there were correlations between $\mathrm{C} 18$ :1-Cer and serum insulin levels $(R=0.21, p \leq 0.05)$ and HOMA- $\beta(R=0.21, p \leq 0.05)$, as well as between C24:1-Cer and insulin level $(\mathrm{R}=0.22, p \leq 0.05)$ and HOMA- $\beta(\mathrm{R}=0.29, p \leq 0.05)$.

Wilcoxon analysis demonstrated progressive changes in ceramide concentration levels during pregnancy (Table 4). We compared measurements from the first trimester with measurements from the second trimester. The most relevant change was observed in 
NGT C24:0-Cer in the second trimester. This appeared to be higher compared to the first $(p<0.001)$. Levels of C16:0-Cer and C18:0-Cer in the GDM group were increased while these parameters were stable in the NGT group. C24:1-Cer in the GDM group was higher in the first trimester than in the second; the NGT group had the opposite situation, but it was not significant. Moreover, the concentration of C18:1-Cer in GDM decreased during pregnancy, but it increased in NGT.

Table 4. The concentration of sphingolipids in the serum of patients from the GDM and NGT groups by trimester.

\begin{tabular}{|c|c|c|c|c|c|c|c|c|}
\hline \multirow{3}{*}{ Compound } & \multicolumn{4}{|c|}{ NGT } & \multicolumn{4}{|c|}{ GDM Converters } \\
\hline & \multicolumn{2}{|c|}{ 1st Trimester } & \multicolumn{2}{|c|}{ 2nd Trimester } & \multicolumn{2}{|c|}{ 1st Trimester } & \multicolumn{2}{|c|}{ 2nd Trimester } \\
\hline & Me & Q1-Q3 & Me & Q1-Q3 & Me & Q1-Q3 & Me & Q1-Q3 \\
\hline Sph & 18.02 & $13.3-31.7$ & 18.7 & $15.3-23.7$ & 17.2 & $14.5-36.9$ & 18.07 & $15.4-20.8$ \\
\hline SPA & 13.89 & 9.9-19.7 & 16.14 & $12.6-21.5$ & 10.82 & $8.0-20.2$ & 14.71 & $10.9-18.5$ \\
\hline S1P & 348.81 & 251.4-403.4 & 307.53 & $214.1-423.3$ & 296.78 & $235.3-342.4$ & 263.73 & $180.9-304.2$ \\
\hline C14:0 Cer & 32.4 & $25.6-42.9$ & 35.87 & $23.9-42.6$ & 29.6 & $23.4-36.7$ & 35.47 & $27.8-43.4$ \\
\hline C16:0 Cer & 183.37 & $151.3-246.6$ & 184.34 & 133.8-234.7 & 178.01 * & 129.9-201.4 & 214.38 * & 178.5-250.2 \\
\hline C18:1 Cer & $20.72 *$ & $16.6-23.7$ & $22.36^{*}$ & $17.7-25.9$ & $24.16^{*}$ & $20.1-29.5$ & $20.36 *$ & $15.6-26.5$ \\
\hline C18:0 Cer & 133.01 & 108.4-160.5 & 137.56 & 116.9-154.6 & $132.87^{*}$ & 108.8-199.6 & $168.21 *$ & 138.4-201.0 \\
\hline C20:0 Cer & 172.96 & 130.1-194.2 & 174.51 & $136.7-210.6$ & 152.08 & 123.6-177.9 & 180.41 & $146.8-242.8$ \\
\hline C22:0 Cer & 280.68 & $243.5-317.7$ & 296.23 & $248.7-347.2$ & 316.04 & $256.0-376.7$ & 278.25 & $237.0-336.5$ \\
\hline C24:1 Cer & 280.36 & $237.9-336.5$ & 285.22 & $234.5-344.5$ & 278.96 * & $241.5-320.3$ & $257.62 *$ & $214.8-296.6$ \\
\hline C24:0 Cer & $2200.14^{\circ}$ & $2040.8-2608.7$ & $2612.07^{\circ}$ & 2306.4-2936.5 & 2356.23 & 2026.8-2917.9 & 2545.29 & 2115.7-3077.4 \\
\hline Cer Total & 3344.21 & 3101.9-3682.7 & 3731.5 & $3494.8-4298.8$ & 3552.17 & $3007.1-3923.5$ & 3737.46 & $3310.1-4454.1$ \\
\hline
\end{tabular}

This table shows changes during pregnancy. Data are presented as medians and interquartile range; ${ }^{*} p<0.05$; ${ }^{\circ} p<0.001$. Analysis was performed with Wilcoxon test.

Comparison of sphingolipid concentrations measured in the second trimester of pregnancy showed prominent differences between the GDM and NGT group in terms of S1P $(p=0.009), C 16: 0-C e r(p=0.04), C 18: 0-C e r(p=0.0002)$, and C24:1-Cer $(p=0.03)$. The diagnostic value of those sphingolipids was evaluated by ROC analysis. The values of AUC and optimal cut-off value for S1P were 0.638 (95\% confidence interval: $0.541-0.735$; $p=0.005)$ and $304.15 \mathrm{ng} / \mathrm{mL}$. AUC was 0.606 (95\% confidence interval: $0.508-0.705 ; p=0.03)$ and the cut-off value was $184.67 \mathrm{ng} / \mathrm{mL}$ for C16:0-Cer. AUC was 0.696 (95\% confidence interval: $0.6-0.792 ; p=0.0001)$ and the cut-off value was $155.95 \mathrm{ng} / \mathrm{mL}$ for C18:0-Cer. AUC $=0.618(95 \%$ confidence interval: $0.519-0.718 ; p=0.02)$ and the cut-off value was $272.16 \mathrm{ng} / \mathrm{mL}$ for C24:1-Cer.

\section{Discussion}

The data show that the main pathophysiological dysfunction in GDM is the increasing insulin resistance and insufficient insulin compensation, usually as a result of the $\beta$-cell impairment [1,22]. Sphingolipids, particularly ceramides, are potential factors contributing to diabetes [23]. Our study was designed to measure and compare the changes in circulating sphingolipids concentration in pregnancy and in GDM. It is worth mentioning that, according to O'Sullivan, Carpenter and Coustan [24] and some associations, such as the Spanish Group of Diabetes and Pregnancy (GEDE) [25], OGTT should be taken with $100 \mathrm{~g}$ of glucose and measured in a fasting state, 60, 120, and $180 \mathrm{~min}$ after overload. However, Cabrera-Fernandez et al. [26] revealed that using the GEDE criteria measurement at $180 \mathrm{~min}$ could be omitted. In our work, we applied criteria recommended by the International Association of Diabetes and Pregnancy Study Group (IADPSG) [24] and the International Diabetes Federation (IDF) [27], where $75 \mathrm{~g}$ of glucose is used, and the test lasts $120 \mathrm{~min}$.

This study showed that the total concentration of circulating ceramides measured in the first trimester of pregnancy was significantly higher in pregnant patients versus healthy, non-pregnant women. The pregnant women group showed a significant increase in C16:0-Cer, C 18:1-Cer, C22:0-Cer, C24:1-Cer, and C24:0-Cer. It is known that ceramide biosynthesis is enhanced by insulin in skeletal muscles [28]. During pregnancy, insulin 
resistance increases, and the same insulin concentration is higher. This might explain the increasing ceramide levels.

Elevated C16:0-Cer concentrations have been found in overweight patients and those with type 2 diabetes $[29,30]$. Here, we excluded the possibility of obesity influencing the results. The groups were selected so that they did not present differences in the BMI. However, we show significantly increased C16:0-Cer levels between the first trimester and the second trimester in patients who developed GDM. Raichur et al. [30] reported that the inhibition of synthesis of C16:0-Cer improved insulin resistance and decreased hyperglycemia. They also reported that C16:0-Cer is an important factor in diabetes development, and our study confirmed this theory.

Available data report an association between an increased risk of diabetes development and higher C18:0-Cer levels in plasma [31]. Similarly, in our experiment, in the GDM group this parameter increased during pregnancy and, in the second trimester, was revealed to be significantly higher than in the NGT group where it stayed at a constant level.

Other authors reported increased C18:0, C18:1, C20:0, C22:0, and C24:0-Cer in subjects with a glucose tolerance impairment phenotype $[10,32]$. They also reported a positive association between circulating ceramide levels and insulin-resistance parameters including disruption of $\beta$-cell function and inflammation [32]. During pregnancy, even physiological pregnancy, there is an increase in insulin resistance and a prothrombotic state. This showed pro-inflammatory features [33]. We confirmed a positive correlation between C22:0-Cer and insulin levels and HOMA-IR, as well as between C18:1, C24:0, and C24:1 with insulin concentrations and HOMA $\beta$ across the entire study population. Considering the subgroups, we noted that the GDM converters group's C24:1 positively correlated with insulin concentration and HOMA $\beta$.

Khan et al. [9] recently employed artificial intelligence and demonstrated the predictive value of reduced ceramide levels in the pathophysiology of transition from GDM to type 2 diabetes. Suppression of ceramide synthesis in pancreatic islets impairs glucosestimulated insulin secretion. This discovery suggests that any imbalance may contribute to insulin resistance. Further research into the role of ceramides and mechanisms underlying GDM and diabetes development-especially in the pathophysiology of $\beta$-cells dysfunction and insulin resistance-is required.

Early in pregnancy, fat accumulation occurs due to an increased lipid synthesis and hyperphagia; in the last trimester of pregnancy, fat accumulation halts due to decreased adipose tissue lipoprotein lipase activity [5]. Adipose tissue is an endocrine organ, and its adipocytes synthesize i.a. adiponectin. This adipokine was found to elicit broad spectrum antidiabetic action by activating ceramidase to degrade ceramides [34]. Adiponectin receptors have a homology with ceramidase enzymes. They can activate or deplete adiponectin receptors to markedly alter cellular ceramidase activity [35]. It is known that decreased levels of adiponectin during pregnancy indicates an increased risk of GDM [36].

The pregnant women in our study had lower SPA and S1P levels compared to healthy, non-pregnant women. It is known that S1P is a powerful bioactive lipid that can act intracellularly and extracellularly, and its receptors are widely expressed in the human body [37]. S1P is carried on apolipoprotein M (apoM) [8], a minor apolipoprotein on HDL [9]; it has been proposed to be responsible for many of the pleiotropic qualities of HDL, i.e., having antiapoptotic [10], anti-inflammatory [38], and vasoprotective effects [39].

Recent studies demonstrated the crucial role of S1P in insulin sensitivity and glucose homeostasis. Kurano et al. [40] provided evidence that at least a part of HDL's antidiabetic action involves apolipoprotein $\mathrm{M}(\mathrm{apoM})$ and its lipid ligand sphingosine-1-phosphate (S1P); these are two quantitatively minor components of HDL. They demonstrated that apoM/S1P protects against the development of insulin resistance in the liver, adipose tissue, and skeletal muscles by activating AKT and AMPK signaling, which are the main signaling pathways and act via S1P1 and/or S1P3 by enhancing mitochondrial functions, perhaps through the upregulation of the SIRT1 protein levels. 
A prior study with an animal model showed that increased glycemia resulted in activation of sphingosine kinase isoform 2 (Sphk2) in pancreatic $\beta$-cells and prominently increased S1P. Knockdown of Sphk2 led to the abolition of insulin secretion in response to glucose [41]. Liu et al. [42] proved that S1P prevents $\beta$-cell apoptosis-thus, the authors suggested inhibition of the voltage-dependent potassium channel in pancreatic $\beta$-cells, which also induces $\mathrm{Ca}^{2+}$ inflow into the cell to stimulate insulin secretion.

The literature suggests elevated levels of SPA in type 2 diabetes patients versus healthy control subjects [43]. Moreover, SPA was shown to negatively correlate with insulin sensitivity [44]. In contrast to those reports, we present, here, decreased levels of SPA in the GDM group versus the control group. This may be due to the use of SPA for ceramide synthesis-it is a major precursor in the de novo synthesis pathway [45].

Interestingly, our study demonstrated that the C18:1-Cer level was significantly higher in GDM converters than in the NGT group in the first trimester. It is worth emphasizing that this was the only difference between those groups considering measured sphingolipids, as well as clinical/biochemical parameters. Thus, we suspect that C18:1-Cer may be a potential GDM biomarker. It can manifest a predisposition for disease development before glycemic changes occur. Our results demonstrate that ceramide levels are elevated in pregnancy and changes in the ceramide profile are not independent of BMI. We are aware of only one report about circulating ceramides in early pregnancy. Liu et al. [46] selected the studied groups $(n=486)$ from a large cohort of Chinese women $(n=22302)$. The differences in concentration of ceramides in early pregnancy are significant. Scientists noted that three ceramides were significantly associated with GDM development in later pregnancy. The GDM group showed an increased level of C18:0-Cer and C18:1-Cer and a decreased level of C24:0-Cer. Our results partially confirm this data. We proved only an increase of C18:1-Cer-the remining ceramides showed no significant differences in our groups. Further analysis of ceramides in the second trimester demonstrated that C18:1-Cer concentrations decreased in the GDM serum, but this increased in the NGT group. In contrast to Liu et al., we studied smaller but BMI-matched groups of varying ethnicities.

In summary, our results show differences in the metabolic signature between GDM and control pregnant group in the second trimester of pregnancy. The results emphasize the potential of C 18:1-Cer in the first trimester of pregnancy as a lipidomic biomarker of GDM development. The main limitation of this research was the low number of patients. Furthermore, we did not control for patient diet, which can impact circulating ceramides [47]. Further studies are required to validate our data and to clarify and improve the understanding of GDM pathophysiology.

Author Contributions: Conceptualization, I.J. and M.K.; methodology, A.B.-Z. and A.K.; formal analysis, P.Z. and J.S.; writing-original draft preparation, I.J. and M.K.; writing-review and editing, A.B.-Z. and J.S.; supervision, J.S. and A.K. All authors have read and agreed to the published version of the manuscript.

Funding: This research was funded by the Medical University of Bialystok, Poland, grant number: N/ST/MN/17/001/1129, SUB/1/DN/19/001/1129, SUB/1/DN/19/002/1129.

Institutional Review Board Statement: The study was conducted in accordance with the Declaration of Helsinki, and approved by the Institutional Review of Medical University of Bialystok (R-I002/176/2018, date of approval: 26 April 2018).

Informed Consent Statement: Informed consent was obtained from all subjects involved in the study.

Data Availability Statement: The datasets used and analyzed during the current study are available from the corresponding author on reasonable request.

Conflicts of Interest: The authors declare no conflict of interest. 


\section{References}

1. Plows, J.F.; Stanley, J.L.; Baker, P.N.; Reynolds, C.M.; Vickers, M.H. The Pathophysiology of Gestational Diabetes Mellitus. Int. J. Mol. Sci. 2018, 19, 3342. [CrossRef] [PubMed]

2. Dirar, A.M.; Doupis, J. Gestational Diabetes from A to Z. World J. Diabetes 2017, 8, 489-511. [CrossRef]

3. Catalano, P.M.; Tyzbir, E.D.; Roman, N.M.; Amini, S.B.; Sims, E.A. Longitudinal Changes in Insulin Release and Insulin Resistance in Nonobese Pregnant Women. Am. J. Obstet. Gynecol. 1991, 165, 1667-1672. [CrossRef]

4. Catalano, P.M.; Tyzbir, E.D.; Wolfe, R.R.; Roman, N.M.; Amini, S.B.; Sims, E.A. Longitudinal Changes in Basal Hepatic Glucose Production and Suppression during Insulin Infusion in Normal Pregnant Women. Am. J. Obstet. Gynecol. 1992, 167, 913-919. [CrossRef]

5. Herrera, E.; Ortega-Senovilla, H. Disturbances in Lipid Metabolism in Diabetic Pregnancy-Are These the Cause of the Problem? Best Pract. Res. Clin. Endocrinol. Metab. 2010, 24, 515-525. [CrossRef] [PubMed]

6. Herrera, E.; Lasunción, M.A.; Gomez-Coronado, D.; Aranda, P.; López-Luna, P.; Maier, I. Role of Lipoprotein Lipase Activity on Lipoprotein Metabolism and the Fate of Circulating Triglycerides in Pregnancy. Am. J. Obstet. Gynecol. 1988, 158, 1575-1583. [CrossRef]

7. $\quad$ Ryckman, K.K.; Spracklen, C.N.; Smith, C.J.; Robinson, J.G.; Saftlas, A.F. Maternal Lipid Levels during Pregnancy and Gestational Diabetes: A Systematic Review and Meta-Analysis. BJOG 2015, 122, 643-651. [CrossRef] [PubMed]

8. Meikle, P.J.; Summers, S.A. Sphingolipids and Phospholipids in Insulin Resistance and Related Metabolic Disorders. Nat. Rev. Endocrinol. 2017, 13, 79-91. [CrossRef]

9. $\quad$ Khan, S.R.; Mohan, H.; Liu, Y.; Batchuluun, B.; Gohil, H.; Al Rijjal, D.; Manialawy, Y.; Cox, B.J.; Gunderson, E.P.; Wheeler, M.B. The Discovery of Novel Predictive Biomarkers and Early-Stage Pathophysiology for the Transition from Gestational Diabetes to Type 2 Diabetes. Diabetologia 2019, 62, 687-703. [CrossRef]

10. Furse, S.; White, S.L.; Meek, C.L.; Jenkins, B.; Petry, C.J.; Vieira, M.C.; Ozanne, S.E.; Dunger, D.B.; Poston, L.; Koulman, A. Altered Triglyceride and Phospholipid Metabolism Predates the Diagnosis of Gestational Diabetes in Obese Pregnancy. Mol. Omics 2019, 15, 420-430. [CrossRef]

11. MacRae, V.E.; Burdon, T.; Ahmed, S.F.; Farquharson, C. Ceramide Inhibition of Chondrocyte Proliferation and Bone Growth Is IGF-I Independent. J. Endocrinol. 2006, 191, 369-377. [CrossRef]

12. Oh, H.L.; Seok, J.Y.; Kwon, C.H.; Kang, S.K.; Kim, Y.K. Role of MAPK in Ceramide-Induced Cell Death in Primary Cultured Astrocytes from Mouse Embryonic Brain. Neurotoxicology 2006, 27, 31-38. [CrossRef]

13. Summers, S.A. Ceramides in Insulin Resistance and Lipotoxicity. Prog. Lipid. Res. 2006, 45, 42-72. [CrossRef]

14. Reali, F.; Morine, M.J.; Kahramanoğulları, O.; Raichur, S.; Schneider, H.-C.; Crowther, D.; Priami, C. Mechanistic Interplay between Ceramide and Insulin Resistance. Sci. Rep. 2017, 7, 41231. [CrossRef]

15. Petersen, M.C.; Shulman, G.I. Roles of Diacylglycerols and Ceramides in Hepatic Insulin Resistance. Trends Pharmacol. Sci. 2017, 38, 649-665. [CrossRef]

16. Summers, S.A.; Garza, L.A.; Zhou, H.; Birnbaum, M.J. Regulation of Insulin-Stimulated Glucose Transporter GLUT4 Translocation and Akt Kinase Activity by Ceramide. Mol. Cell. Biol. 1998, 18, 5457-5464. [CrossRef]

17. Samad, F.; Hester, K.D.; Yang, G.; Hannun, Y.A.; Bielawski, J. Altered Adipose and Plasma Sphingolipid Metabolism in Obesity: A Potential Mechanism for Cardiovascular and Metabolic Risk. Diabetes 2006, 55, 2579-2587. [CrossRef] [PubMed]

18. Obinata, H.; Hla, T. Sphingosine 1-Phosphate and Inflammation. Int. Immunol. 2019, 31, 617-625. [CrossRef] [PubMed]

19. Diagnostic Criteria and Classification of Hyperglycaemia First Detected in Pregnancy: A World Health Organization Guideline. Diabetes Res. Clin. Pract. 2014, 103, 341-363. [CrossRef] [PubMed]

20. Matsuda, M.; DeFronzo, R.A. Insulin Sensitivity Indices Obtained from Oral Glucose Tolerance Testing: Comparison with the Euglycemic Insulin Clamp. Diabetes Care 1999, 22, 1462-1470. [CrossRef]

21. Blachnio-Zabielska, A.U.; Persson, X.-M.T.; Koutsari, C.; Zabielski, P.; Jensen, M.D. A Liquid Chromatography/Tandem Mass Spectrometry Method for Measuring the in Vivo Incorporation of Plasma Free Fatty Acids into Intramyocellular Ceramides in Humans. Rapid Commun. Mass Spectrom. 2012, 26, 1134-1140. [CrossRef]

22. Pridjian, G.; Benjamin, T.D. Update on Gestational Diabetes. Obstet. Gynecol. Clin. N. Am. 2010, 37, 255-267. [CrossRef]

23. Haus, J.M.; Kashyap, S.R.; Kasumov, T.; Zhang, R.; Kelly, K.R.; DeFronzo, R.A.; Kirwan, J.P. Plasma Ceramides Are Elevated in Obese Subjects with Type 2 Diabetes and Correlate with the Severity of Insulin Resistance. Diabetes 2009, 58, 337-343. [CrossRef]

24. Bhavadharini, B.; Uma, R.; Saravanan, P.; Mohan, V. Screening and Diagnosis of Gestational Diabetes Mellitus-Relevance to Low and Middle Income Countries. Clin. Diabetes Endocrinol. 2016, 2, 13. [CrossRef]

25. Codina, M.; Corcoy, R.; Goya, M.M. Actualización Urgente: Alternativa Temporal Para El Diagnóstico de Hiper-Glucemia Gestacional y El Seguimiento de Estas Mujeres y Aquellas Con Diabetes Pregestacional Durante La Pandemia COVID-19. Consenso Del Grupo Español de Diabetes y Embarazo (GEDE) de La Sociedad Española de Diabetes (SED) y La Sociedad Española de Ginecología y Obstetricia (SEGO). Endocrinol. Diabetes Nutr. 2020, 67, 545-552. [CrossRef]

26. Fernández, S.C.; Martínez, M.M.; De Francisco Montero, C.; Rodríguez, I.G.; Arenas, Á.V.; Calvo, M.O. Predictive models of gestational diabetes, a new prediction mode. Semergen 2021, 47, 515-520. [CrossRef]

27. IDF Diabetes Atlas. 2021. Available online: www.diabetesatlas.org (accessed on 6 December 2021).

28. Hansen, M.E.; Tippetts, T.S.; Anderson, M.C.; Holub, Z.E.; Moulton, E.R.; Swensen, A.C.; Prince, J.T.; Bikman, B.T. Insulin Increases Ceramide Synthesis in Skeletal Muscle. J. Diabetes Res. 2014, 2014, 765784. [CrossRef] 
29. Turpin, S.M.; Nicholls, H.T.; Willmes, D.M.; Mourier, A.; Brodesser, S.; Wunderlich, C.M.; Mauer, J.; Xu, E.; Hammerschmidt, P.; Brönneke, H.S.; et al. Obesity-Induced CerS6-Dependent C16:0 Ceramide Production Promotes Weight Gain and Glucose Intolerance. Cell Metab. 2014, 20, 678-686. [CrossRef]

30. Raichur, S.; Brunner, B.; Bielohuby, M.; Hansen, G.; Pfenninger, A.; Wang, B.; Bruning, J.C.; Larsen, P.J.; Tennagels, N. The Role of C16:0 Ceramide in the Development of Obesity and Type 2 Diabetes: CerS6 Inhibition as a Novel Therapeutic Approach. Mol. Metab. 2019, 21, 36-50. [CrossRef]

31. Fretts, A.M.; Jensen, P.N.; Hoofnagle, A.; McKnight, B.; Howard, B.V.; Umans, J.; Yu, C.; Sitlani, C.; Siscovick, D.S.; King, I.B.; et al. Plasma Ceramide Species Are Associated with Diabetes Risk in Participants of the Strong Heart Study. J. Nutr. 2020, 150, 1214-1222. [CrossRef]

32. Kayser, B.D.; Prifti, E.; Lhomme, M.; Belda, E.; Dao, M.-C.; Aron-Wisnewsky, J.; Kontush, A.; Zucker, J.-D.; Rizkalla, S.W.; Dugail, I.; et al. Elevated Serum Ceramides Are Linked with Obesity-Associated Gut Dysbiosis and Impaired Glucose Metabolism. Metabolomics 2019, 15, 140. [CrossRef]

33. Soma-Pillay, P.; Catherine, N.-P.; Tolppanen, H.; Mebazaa, A.; Tolppanen, H.; Mebazaa, A. Physiological Changes in Pregnancy. Cardiovasc. J. Afr. 2016, 27, 89-94. [CrossRef]

34. Holland, W.L.; Miller, R.A.; Wang, Z.V.; Sun, K.; Barth, B.M.; Bui, H.H.; Davis, K.E.; Bikman, B.T.; Halberg, N.; Rutkowski, J.M.; et al. The Pleiotropic Actions of Adiponectin Are Initiated via Receptor-Mediated Activation of Ceramidase Activity. Nat. Med. 2011, 17, 55-63. [CrossRef]

35. Vasiliauskaité-Brooks, I.; Sounier, R.; Rochaix, P.; Bellot, G.; Fortier, M.; Hoh, F.; De Colibus, L.; Bechara, C.; Saied, E.M.; Arenz, C.; et al. Structural Insights into Adiponectin Receptors Suggest Ceramidase Activity. Nature 2017, 544, 120-123. [CrossRef]

36. de Gennaro, G.; Palla, G.; Battini, L.; Simoncini, T.; Del Prato, S.; Bertolotto, A.; Bianchi, C. The Role of Adipokines in the Pathogenesis of Gestational Diabetes Mellitus. Gynecol. Endocrinol. 2019, 35, 737-751. [CrossRef]

37. Hla, T.; Dannenberg, A.J. Sphingolipid Signaling in Metabolic Disorders. Cell Metab. 2012, 16, 420-434. [CrossRef]

38. Frej, C.; Mendez, A.J.; Ruiz, M.; Castillo, M.; Hughes, T.A.; Dahlbäck, B.; Goldberg, R.B. A Shift in ApoM/S1P Between HDLParticles in Women with Type 1 Diabetes Mellitus Is Associated with Impaired Anti-Inflammatory Effects of the ApoM/S1P Complex. Arter. Thromb. Vasc. Biol. 2017, 37, 1194-1205. [CrossRef]

39. Del Gaudio, I.; Sreckovic, I.; Zardoya-Laguardia, P.; Bernhart, E.; Christoffersen, C.; Frank, S.; Marsche, G.; Illanes, S.E.; Wadsack, C. Circulating Cord Blood HDL-S1P Complex Preserves the Integrity of the Feto-Placental Vasculature. Biochim. Biophys. Acta Mol. Cell Biol. Lipids 2020, 1865, 158632. [CrossRef]

40. Kurano, M.; Tsukamoto, K.; Shimizu, T.; Kassai, H.; Nakao, K.; Aiba, A.; Hara, M.; Yatomi, Y. Protection Against Insulin Resistance by Apolipoprotein M/Sphingosine-1-Phosphate. Diabetes 2020, 69, 867-881. [CrossRef]

41. Stanford, J.C.; Morris, A.J.; Sunkara, M.; Popa, G.J.; Larson, K.L.; Özcan, S. Sphingosine 1-Phosphate (S1P) Regulates GlucoseStimulated Insulin Secretion in Pancreatic Beta Cells. J. Biol. Chem. 2012, 287, 13457-13464. [CrossRef]

42. Liu, Z.; Yang, H.; Zhi, L.; Xue, H.; Lu, Z.; Zhao, Y.; Cui, L.; Liu, T.; Ren, S.; He, P.; et al. Sphingosine 1-Phosphate Stimulates Insulin Secretion and Improves Cell Survival by Blocking Voltage-Dependent K+ Channels in $\beta$ Cells. Front. Pharmacol. 2021, 12, 683674. [CrossRef]

43. Górska, M.; Dobrzyń, A.; Baranowski, M. Concentrations of Sphingosine and Sphinganine in Plasma of Patients with Type 2 Diabetes. Med. Sci. Monit. 2005, 11, CR35-CR38.

44. Straczkowski, M.; Kowalska, I.; Nikolajuk, A.; Dzienis-Straczkowska, S.; Kinalska, I.; Baranowski, M.; Zendzian-Piotrowska, M.; Brzezinska, Z.; Gorski, J. Relationship Between Insulin Sensitivity and Sphingomyelin Signaling Pathway in Human Skeletal Muscle. Diabetes 2004, 53, 1215-1221. [CrossRef] [PubMed]

45. Tidhar, R.; Futerman, A.H. The Complexity of Sphingolipid Biosynthesis in the Endoplasmic Reticulum. Biochim. Biophys. Acta 2013, 1833, 2511-2518. [CrossRef]

46. Liu, J.; Li, J.; Yang, K.; Leng, J.; Li, W.; Yang, W.; Huo, X.; Yu, Z.; Cw Ma, R.; Hu, G.; et al. Ceramides and Their Interactive Effects with Trimethylamine-N-Oxide Metabolites on Risk of Gestational Diabetes: A Nested Case-Control Study. Diabetes Res. Clin. Pract. 2021, 171, 108606. [CrossRef] [PubMed]

47. Mathews, A.T.; Famodu, O.A.; Olfert, M.D.; Murray, P.J.; Cuff, C.F.; Downes, M.T.; Haughey, N.J.; Colby, S.E.; Chantler, P.D.; Olfert, I.M.; et al. Efficacy of Nutritional Interventions to Lower Circulating Ceramides in Young Adults: FRUVEDomic Pilot Study. Physiol. Rep. 2017, 5, e13329. [CrossRef] [PubMed] 